\title{
Invoking and Supporting Engineering Student Mathematical Thnking in Informal Cooperative Learning Classroom
}

\author{
Sabariah Baharun ${ }^{a^{*}}$, Yudariah Mohammad Yusof $^{b}$, Roselainy Abdul Rahmanc ${ }^{\text {, Zaleha Ismaild }}$ \\ aMalaysia-Japan International Institute of Technology (MJIIT), University Teknologi Malaysia, Kuala Lumpur \\ ${ }^{b}$ Centre of Engineering Education, University Teknologi Malaysia, 81310 Johor Bahru, Malaysia \\ CUTM Razak School of Engineering and Advanced Technology, University Teknologi Malaysia, Kuala Lumpur \\ ${ }^{d}$ Faculty of Education, University Teknologi Malaysia, 81310 Johor Bahru, Malaysia \\ *Corresponding author: sabariahb@utm.my
}

\begin{abstract}
Through our experience in teaching mathematics to engineering undergraduates, we found that students had numerous difficulties with the mathematics learned. Although our students have demonstrated the ability to answer standard or routine questions, there were still some inconsistencies between their ability to answer questions and their understanding of the concepts and the mathematical procedures they were using. In previous work, we had highlighted the importance of mathematical thinking and adopted suitable approaches in teaching and learning of engineering mathematics. However, innovative strategies were deemed necessary to assist students in their learning. In this paper, we will share how we transform our teaching practice to facilitate the development of students' ability in understanding the various mathematical concepts, in reconstructing them as parts of a whole through cooperative learning. The approach allows them to develop efficient strategies in constructing new knowledge and be empowered with more successful ways of thinking about mathematics and solving problems. Here, we will share our experience in translating some of the theories into classroom practice through informal cooperative learning environment. Data were gathered through our own reflections, classroom observation, and interviews with the students. We will bring to light the findings on the students' ability to solve problems related to the topics learned and discuss the implications for effective mathematics teaching and learning of prospective engineers.
\end{abstract}

Keywords: Mathematical knowledge development; thinking skills; engineering undergraduates

(C) 2017 Penerbit UTM Press. All rights reserved

\subsection{INTRODUCTION}

The demands for graduates who can think critically, solve problems and can communicate, to name a few, are highly sought after in the workplace (McCray, 2001, Harris et al., 2015). Therefore, the development of such skills was recognized as integral goals of undergraduate education at UTM. In particular, rigorous efforts have been made to inculcate these skills amongst engineering students at MJIIT since 2011 when it received the first cohort of engineering undergraduates. Our work focused on the mathematics education of prospective engineers. Malaysia-Japan International Institute of Technology (MJIT), has adopted a teaching and learning culture by focusing on Knowledge, Experiential and Self-regulated learning (KES). How are we coping with the challenges of changing our teaching practices to accommodate this noble quest? What innovative strategies should be incorporated into mathematics classes to prepare future engineers for the ways in which they will be expected to function in the workplace? How do we ensure the mathematical skills acquired by the students would help them in the understanding of engineering principles and are able to apply these skills to solve practical problems?

Generally at UTM as well as at MJIIT, the mathematics curriculum is mainly taught as service courses. The implicit assumptions have always been if students understand the mathematics learnt, they should be able to transfer and use their mathematical knowledge in their engineering courses. However, findings from previous research (Yudariah \& Roselainy, 2004; Roselainy, Yudariah \& Mason, 2005; Roselainy, Yudariah \& Sabariah. 2007; Roselainy, 2009; Kashefi et al., 2010; Roselainy et al., 2012; Kashefi et al., 2012; Yudariah et al., 2014) have shown that the transfer of learning does not occur as efficiently as we would have expected. We have encountered students who had difficulties in manipulating concepts, coordinating multiple procedures, manipulating symbols in a flexible way and in answering nonroutine questions. Other research further corroborates our observations (Anthony, 2000; Engineering Council, 2000; Croft \& Ward, 2001; Townend, 2001; Hoch \& Dreyfus, 2005, Ferri 2012, Goold \& Devitt, 2013).

Most engineers recognize the powers of mathematical thinking that gives them a means of formulating, analyzing and solving a wide range of practical problems. We have been working to support and enhance students' mathematical thinking powers in mathematics learning. In our previous work, a framework was developed based on the work of Mason et al., (1982, 2010), Watson \& Mason (1998), and Tall (1993, 1995, 2013). This framework makes the thinking processes and the structures of mathematics explicit to support and to enhance students' awareness on the use of their own thinking powers as well as to highlight independent learning, communication and team working skills. The framework is described in greater detail in Roselainy et al., (2007), Sabariah et al., (2008), Roselainy (2009) and Roselainy et al., (2012). 
These work also suggested some factors that influenced students' mathematics learning behaviour which included beliefs about how to study, habits adopted from their pre-university experience, rewards, motivation and a tendency to depend on teachers' guidance. Factors such as motivation and rapport with lecturers have significantly influenced students' awareness and desire to change their learning behaviour. These factors need to be duly considered in designing an effective classroom environment that support, develop and extend student mathematical ability. Accordingly a new model, known as Teaching and Learning Model, was designed to further extend the framework and included strategies to support students' awareness of their Self-Regulated Learning (SRL) (Pintrich \& Zusho, 2002; Zimmerman, 2000).

In this paper, we will share our work on implementing the new model to enhance students' mathematical learning by invoking their use of own thinking in an environment that gives them the opportunity to work together in a shared task to construct their knowledge and understanding of the mathematics. Our attempt in transforming the classroom practice gives indication of the impacts on students' mathematics learning.

\subsection{THE APPROACH}

The study is guided by a conceptual framework that was refined from an earlier model by Roselainy et al., (2012). We used action research enquiry to elicit data related to students' perception of their learning and the assessment practice.

\section{Teaching and Learning Model}

The refined framework, that is the Teaching and Learning Model, includes students' SRL (see Figure 1). It categorizes the learning situation into three components: (1) the course learning outcomes, (2) the teaching and learning and assessment (TLA) activities and tasks and (3) the environment supporting the SRL processes (Roselainy et al., 2014).



Figure 1 Model of the teaching and learning situation

SRL is demonstrated through the students' ability to independently plan, monitor, and assess their learning. To be effective learners, students have to learn and develop these skills. Based on the model, an environment to support students' awareness of SRL processes and engagement in SRL was designed. Whilst, to invoke and promote students' awareness of their own mathematical thinking powers and knowledge construction, we used our workbook (Yudariah et al., 2011).

\section{Classroom Environment}

The new teaching and Learning model was used as the underlying principle in designing the teaching approach for a course on multivariable calculus. We adopt the informal cooperative learning as an instructional approach to encourage independent learning but included activities to promote group work. Firstly, students have to work on the topics by reading the text or notes on their own. This is followed by the discussion of the concepts and working on examples as well as the exercises in their groups. To monitor the class progress, lecturers worked in pairs to act as facilitators and to attend to the students in their groups. The mode of delivery remains fluid, anticipating the students' needs, for example, some mathematical examples were explained to students in a lecture setting, and in the case of a topic found difficult by the students, a lecture may be delivered. The teaching sessions were conducted twice a week in two-hour duration. The sessions also incorporated students' presentations at the end of every chapter. Students have to present answers to questions developed to check their understanding of concepts as well as answers to some exercises and to explain the procedures used.

In creating a learning environment to support students in adopting SRL, the processes in SRL was translated into teaching practice in the following way. There are three components in SRL, Forethought and planning, Performance monitors and Reflection monitoring.

1) Forethought and planning: Students were given the Course Outline at the beginning of the semester that contained information about the course outcomes, weekly schedule, Students' Learning Time calculation and the detailed assessment information. In addition, they 
were also provided Learning Guides containing information on topics outcomes, time allocation for each topic and sub-topic and the assignment questions. They were encouraged to manage their own learning by using these guides;

2) Performance monitoring: A section referred as Making Sense was introduced. Questions were asked to increase students' awareness of how to monitor their knowledge and mathematical skills development. The questions focused on students' understanding of the concepts taught and their awareness on the mathematical procedures and techniques. Answers to the questions were reviewed by the lecturer who later compared the students' performance in the assessment tasks. If a particular question in the assignment was wrongly or poorly answered by a number of students, the misunderstanding or mistakes were then addressed by the lecturer in class. Feedback, both verbal and written was given to students to help them improve learning;

3) Reflections monitoring: Another section in the book, named Reflections contains extra questions that inquired the students' ability to manage their study, time, emotional responses to the study, what they considered as effective learning strategies, learning difficulties and strategies to overcome those difficulties and perceptions throughout the sessions. These questions provoked the students to evaluate their strengths, weaknesses, preferences about the course, teaching and learning as well as suggestions on aspects of the course they would like to be changed. These self-reflections acted as a catalyst to influence students' planning and goals setting in their learning. The responses were collected to inform the lecturer of the students' concerns and allow them to address accordingly in the next class.

\section{Participants}

The teaching and learning model was implemented in Engineering Mathematics 3 course taken by second year undergraduates in the Electronic Systems Engineering (ESE) and Mechanical Precision Engineering (MPE) programmes at for the 2012/2013 and 2013/2014 sessions. Various informal cooperative learning strategies were applied to promote active learning in order to develop (i) positive interdependence, (ii) individual accountability, (iii) face-to-face interaction, (iv) inter-personal skills and (v) self- assessment of group functioning (Felder \& Brent, 2008). These strategies will also help the SRL processes. Some of the strategies used includes, open questioning, reflection, read and explain teams and team summaries. Other strategies are included as deemed suitable.

Data was collected through a survey administered to the cohort at the end of the semester. Students' responses to the teaching, their mathematical thinking development and self-regulation items gave indication that students showed some effort to adopt SRL and cooperative learning habits. They participated in discussions, willing to ask for help, shared their concerns and were generally willing to talk about their problems, learning needs and difficulties in mathematics (Roselainy et al., 2014). However, some students' final grades were disappointing, for example, 35\% of ESE students from 2013/14 session had grade C- and below (see Figure 2).

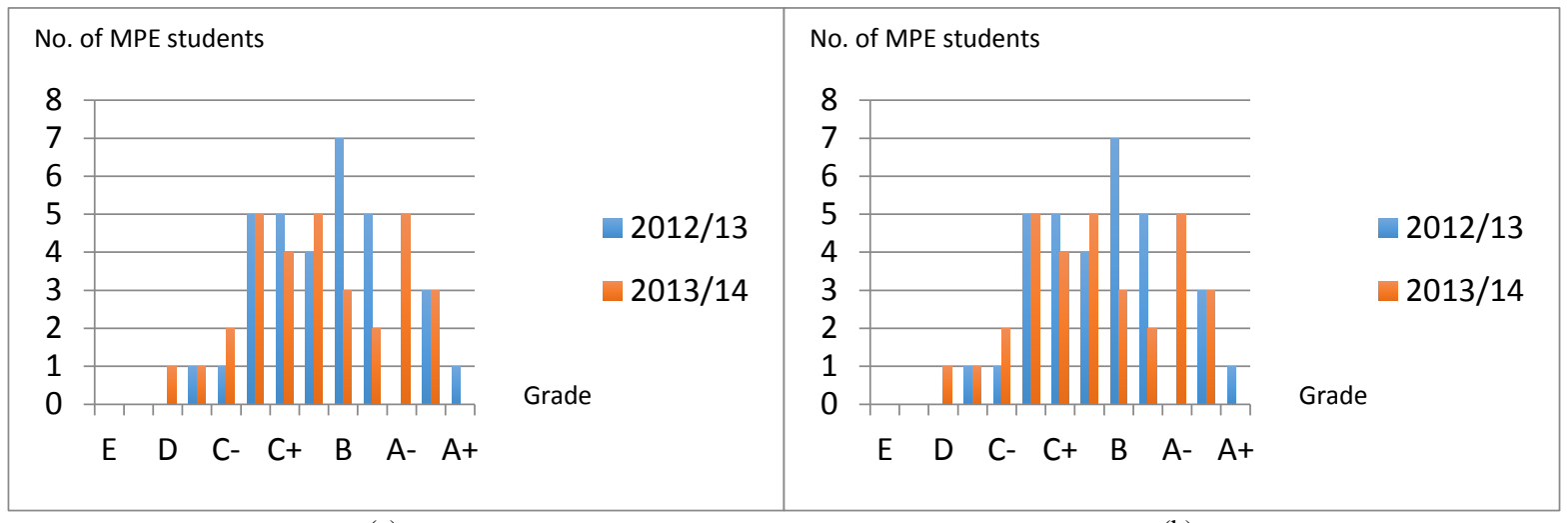

(a)

(b)

Figure 2 Students grades distribution for the 2012/13 and 2013/14 academic

Further modification was then made on the teaching and learning strategies, to accommodate students' preferences, for the subsequent classes in 2014/15 academic session.

\section{Teaching Method}

We maintained the major components of the teaching framework but modified the delivery and assessment. The number of students per class was limited to 25-35 and they work in groups of 3 - 4 people. Informal cooperative learning techniques were continued to be use to facilitate student learning.

For the delivery, the flipped classroom approach was adapted where the students have to read and discuss each new topic within their group, learn to solve the given problems, and engage with the Prompts and Questions to help them make sense of the mathematics and to share their understanding. Learning guides that describe the topic learning outcomes and the duration for each topic were provided to each student to assist them in planning and managing their learning time.

The assessment methods were chosen to assess students learning, used for learning, and as learning, while trying to e a balance between individual and group work. For group work, the students are required to prepare a written report and present the report to the class. In this way, students learn to communicate their understanding of the mathematical concepts. During presentation, their peers could participate by indicating they had understood the explanation, offer corrections or provide different explanations. The lecturer will intervene to address mathematical misconceptions or misuse of the mathematical language, raided but not the presentation. 
At the end of every major chapter or section, a short test was given a week after presentation was made by the students. This test served as the individual assessment and each student is compelled to engage in the group work to ensure understanding of the materials and to prepare him for the test. The sequence read - write report - present - test followed through for each chapters. In addition, the students were also given a small problem-solving project which they needed to solve within the group along with the comprehensive final examination at the end of the semester.

\section{Research Methods, Data Collection and Analysis}

An action research methodology was used as the process has several features that were appropriate to the research concerns. Firstly, action research is an intervention in personal practice with a commitment to educational improvement (Mcniff, Lomax \& Whitehead, 1996). The teacher becomes the subject and object of research but with a greater awareness of the actions that are being carried out. It means that the teacher must investigate her actions and motives systematically, be critical of her interpretations and findings and be more open to alternative viewpoints. There should be a commitment to the actions implemented and the actions must be intentional. The process itself demands that the teacher becomes aware of the cycle of planning, action and review. She must alternate action with critical reflection, evaluating the research situation and back to the planning, modifying or changing if and when required. Secondly, action research will allow authentic description of the classroom environment to be made, the teacher's actions as well as the students' behaviour in the class.

Various methods of collecting data was used, namely, observation of students at work and during their presentation, examples of students' assessment assignments, tests' and examination results, discussion and interviews. The data collected during earlier lessons are quickly analysed and serves to inform subsequent teaching sessions. Test results give an early indication of students' performance. Discussing with students about their performance can help them to improve in later tests. The examination result gives a final indication on students' performance and is used in our reporting of the Course Assessment Review which is submitted at the end of the semester.

Ongoing analysis of the data collected contributes to our own monitoring of our teaching approaches and the choice of tasks for students. Some particular examples, was the modifications of questions asked to elicit students' responses in presenting the understanding of the basic concepts. Questions that were answered differently by different groups indicate poor clarity and have to be revised. Our major concern in this research was to ensure that students were comfortable in examining their mathematical thinking skills and strategies thus during all the face to face sessions, we actively sought to maintain an open space for discussions and questioning. Earlier research has shown that rapport and negotiations are very important to students (Roselainy, 2009).

In particular, data analysis was directed at improving teaching and learning. Thus an important process includes our critical reflection of lessons and students' performance in the assignments. We instituted discussion amongst all the lecturers so as to consolidate our awareness of students' difficulties and achievements. The information is then used an inputs to plan our next lesson. However, the data was also analyzed further to identify students' growth in knowledge and skills. Students' results were also analyzed to identify changes in performance trends.

\subsection{RESULTS AND DISCUSSION}

Data from interviews, questionnaire and observations as well as marks obtained at the end of the semester were analysed to see the impact of the new approach. All the questions in the assignments, tests and final examination were mainly routine focusing on concepts and techniques. Some problem solving at Bloom's cognitive level of 'analyzing' was also included but higher levels of thinking were addressed in the problem solving project. The questions given were of unfamiliar context.

For the problem solving project, we observed that the students made effort to solve the problems and were able to integrate the Prompt and Questions in their work. However, looking at their written work of the problem-solving project, we found inconsistency in the understanding of the concepts. Below is an example of two groups of student response to a problem where they were asked to sketch a softball bat and to find its mass:

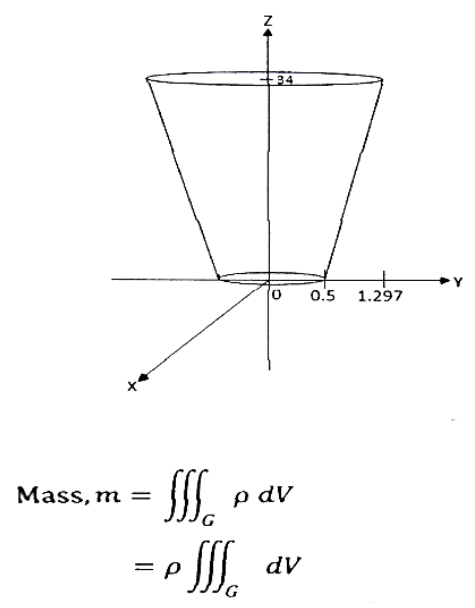

(a)



$$
\begin{aligned}
& \mathbf{m}=\rho \iiint_{G} \mathrm{dV} \\
& =\rho \int_{0}^{2 \pi} \int_{-2}^{30} \int_{0}^{\frac{35}{64}+\frac{3}{128} \mathrm{z}} \mathrm{rdrdzd \theta}
\end{aligned}
$$

(b)

Figure 3 Sample of student respond to the problem-solving project 
Reviewing the overall performance and the grades achieved by the students, the current results were compared to previous results (see Figure 4). Result from the session 2014/15 was compared to results from the sessions 2012/13 and 2013/14.

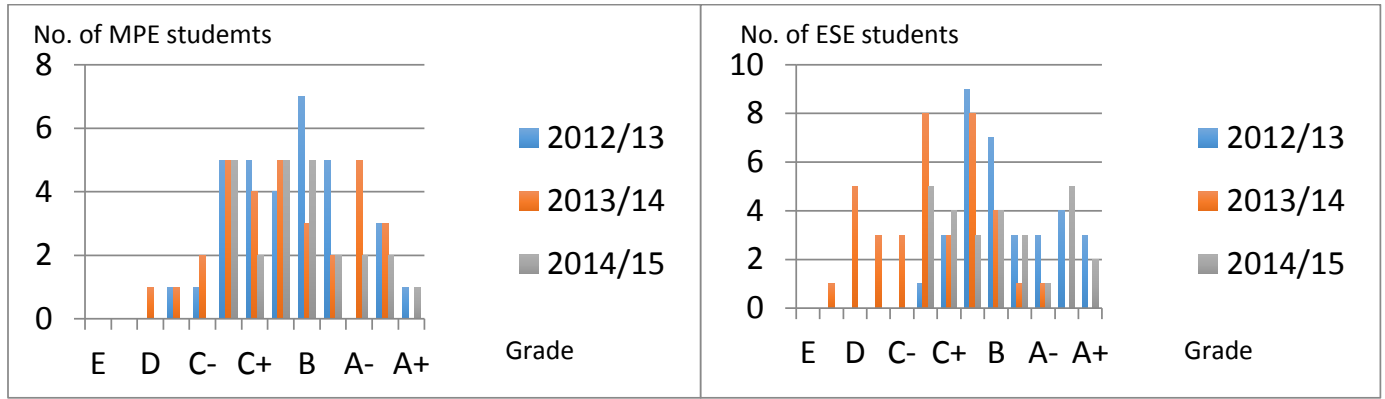

(a)

(b)

Figure 4 Recent grades distribution in the course compared to the previous semesters

It shows there is an increase in the number of students getting grade $\mathrm{C}$ and above. Table 1 lists the overall mean and standard deviations of the general students' results to show some positive increase in average performance. This gives some indication that the new teaching approaches appears to have not only engaged the students in their learning but have improved their performance.

Table 1 Recent students' achievement in the course compared to the previous results

\begin{tabular}{ccccccc}
\hline Session & Program & No. of students & Mean & Std Dev & Min \\
\hline 2012 & MPE & 32 & 64.41 & 12.23 & 40 \\
\cline { 2 - 5 } & ESE & 33 & 69.36 & 11.14 & 56 \\
\hline 13 & MPE & 31 & 61.60 & 12.69 & 38 \\
\hline 14 & ESE & 37 & 52.58 & 10.48 & 33 \\
\hline 2013 & MPE & 24 & 65.09 & 12.34 & 95 \\
\hline 15 & ESE & 27 & 67.26 & 12.86 & 99 \\
\hline
\end{tabular}

A questionnaire was distributed to 106 students at the end of the semester. This questionnaire was divided into three categories looking at their perception on the use of the workbook, the flipped classroom, and the assessment. Based on the feedback, $87 \%$ of the students expressed their agreement while $13 \%$ disagreed. Table 2 summarises the results.

Table 2 Result of the responses of the new approach based on the categories

\begin{tabular}{ccc}
\hline Categories & Agree & Disagree \\
\hline Workbook & $85 \%$ & $15 \%$ \\
\hline Delivery Method & $86 \%$ & $14 \%$ \\
\hline Assessment Technique & $89 \%$ & $11 \%$ \\
\hline
\end{tabular}

Analyzing the responses from the questionnaire and comments that students made in their assignments, students agreed that the approach motivates them to understand the materials better. A majority also agreed that the mode of assessment gave them many opportunities to improve their learning, manage their study and to score well in the tests and the final examination. They enjoyed the class and wished other mathematics classes adopted similar approach. The learning environment had facilitated students' use of their own thinking and improved their communication amongst peers and with us. They were willing to share their difficulties as well as their understanding of the concepts learned.

The changes in the teaching and learning was embarked based on making a holistic change in the teaching, presentation of content, assessment, teaching and learning environment as well as supporting students to initiate change in their learning behaviour.

\subsection{CONCLUSION}

The findings indicate that the changes we made in our teaching practice on student learning have some effect in motivating and supporting better students' performance. The diverse activities had generated the students' interest as well as providing them with opportunities to take charge of their learning. The strategies enabled students to develop ways to start work in solving problems. Thus, they were engaged in the attempts to solve the problems, although they were not necessarily able to solve them completely. They were actively participating in the class, within their groups and manage to enhance their mathematical communication with their peers and with the lecturers. The approach has also motivated students to make more sense of the mathematics learnt and helped them in delivering the material to achieve this aim. 


\section{Acknowledgement}

The authors acknowledge Ministry of Education (MOE) Malaysia, Universiti Teknologi Malaysia (vot no. 4F430) and MJIIT for supporting this research.

\section{References}

Baharun, S., Mohd. Yusof, Y., \& Abdul Rahman, R., (2008). Facilitating Thinking and Communication in Mathematics, DG 24, presented at ICME 11, Mexico.

Mason, J., Burton, L. \& Stacey, K., (1982). Thinking Mathematically. Addison-Wesley Publishing Company, Inc, Wokingham, England.

Mason, J., Burton, L. \& Stacey, K., (2010). Thinking Mathematically. Addison-Wesley Publishing Company, Inc, Wokingham, England.

McNiff, J., Lomax, P. \& Whitehead, J., (1996). You and Your Action Research Project, Routledge \& Hyde Publications, London \& New York.

Pintrich, P. R., \& Zusho, A. (2002). The Development Of Academic Self-Regulation: The Role Of Cognitive And Motivational Factors. In A. Wigfield \& J. Eccles (Eds.), Development Of Achievement Motivation, 249-284. San Diego, CA: Academic Press

Roselainy, Yudariah and Sabariah, (2007). Enhancing Thinking through Active Learning in Engineering Mathematics. Proc. 4th Regional Conf. on Engineering Education, Johor Bahru.

Roselainy Abdul Rahman, (2009). Changing my Own and my Students Attitudes to Calculus Through Working on Mathematical Thinking. Unpublished PhD thesis, Open University, UK

Roselainy, Yudariah and Sabariah, (2012). Realizing Desired Learning Outcomes in Undergraduate Mathematics, In Khairiyah et al.,(Eds), Outcome-Based Science, Technology, Engineering, and Mathematics Education. Innovative Practices, IGI Global, Hershey, USA.

Roselainy, Sabariah, Yudariah and Sharifah Alawiah (2014). Self-Regulated Learning as the Enabling Environment to Enhance Outcome-Based Education of Undergraduate Engineering Mathematics. International Journal of Quality Assurance in Engineering and Technology Education, 3(2), April - June, 43-53.

Tall, D., (1995). Cognitive Growth in Elementary and Advanced Mathematical Thinking, Plenary Lecture, Conf. of International Group of PME, Recife, brazil, 1, p $161-175$.

Tall, D. \& Razali, M. R. (1993). Diagnosing Students' difficulties in Learning Mathematics, Int Jnl of Math Edn in Sc \& Tech, 24(2), 209-222.

Tall, D., (2013). How Humans Learn to Think Mathematically, Cambridge University Press, New York.

Watson, A. \& Mason, J. (1998). Questions and Prompts for Mathematical Thinking. ATM, Derby.

Yudariah Mohd. Yusof, Sabariah Baharun \& Roselainy A. Rahman, (2001). Mathematics Education in UTM: Learning from Experience, Jurnal Teknologi, UTM Press, Johor.

Yudariah Mohd. Yusof, Sabariah Baharun \& Roselainy A. Rahman, (2011). Multivariable Calculus for Independent Learners, Revised 2nd Edition, Pearson Malaysia Sdn Bhd., Kuala Lumpur.

Zimmerman, B. J. (2000). Attaining Self-Regulation: A Social Cognitive Perspective. In M. Boekaerts, P. R. Pintrich, \& M. Zeidner (Eds.), Handbook Of Self-Regulation. San Diego: CA: Academic Press. 